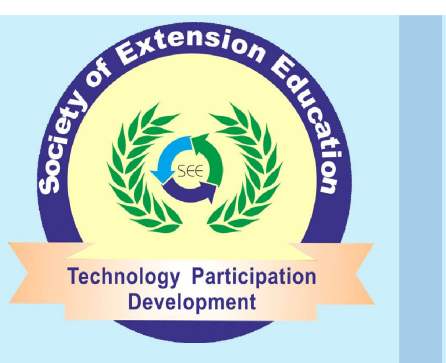

Research Article

\section{Indian Research Journal of Extension Education}

ISSN: 0972-2181 (Print), 0976-1071 (Online)

NAAS Rating : 5.22

Journal homepage: seea.org.in

https://doi.org/10.54986/irjee/2022/jan_mar/44-49

\title{
Information Sources Utilization among Potato Farmers in North East India
}

\author{
Rajib Das ${ }^{1}$ and K. K. Jha ${ }^{2}$ \\ 1. Ph. D Scholar, 2. Prof. \& Head, Dept of Agril. Extension, NU, SASRD, Nagaland \\ Corresponding author e-mail : srajib99@gmail.com \\ Paper Received on August 21, 2021, Accepted on November 12, 2021 and Published Online on January 01, 2022
}

\begin{abstract}
Information technology has transformed many other aspects of human endeavor and has helped create systems for responding to a wide range of societal needs. The benefits of pertinent farm related information in empowering farmer are significant and remain to be exploited. Potato is one of the most important crops grown successfully in North East India but farmers have limited access to the updated information. A research study was undertaken in four major potato growing states of NE including Assam, Meghalaya, Nagaland and Tripura with a sample of 480 farmers. It was found that potato farmers preferred to utilize informal information sources more than formal as well as the mass media sources with respect to using inputs and taking pertinent decisions with respect to sustainable potato cultivation. Farmers urgently require timely and reliable sources of information for taking important farm management decisions. Therefore, it is recommended to popularize the strategic use of mass media including user friendly ICT tools for better and faster outreach to the target farmers.
\end{abstract}

Key words: Information sources; Sustainable potato cultivation; North East India.

$\mathbf{P}_{\text {otato is the most important crop cultivated }}$ worldwide. It is grown in more than 125 countries and consumed almost daily by more than a billion people. Hundreds of millions of people in developing countries depend on potatoes for their survival. Potato cultivation is expanding strongly in the developing world, where the potato's ease of cultivation and nutrient content has made it a valuable for food security and cash crop for millions of farmers. After harvest, potatoes can be used for a variety of purposes such as fresh vegetable for cooking at home, as raw material for processing into food products, food ingredients, starch and alcohol, as feed for animals, and as seed tubers for growing the next season's crop. Potato development and agricultural development in general requires empowerment of small farmers through improved access to production inputs, credit and markets.

The crop is grown throughout the year in one or the other parts of the North Eastern region contributes about 6.30 per cent of the total area under potato and 2.17 per cent production in India $(N H B, 2018)$. Potato crop forms an important part of prevailing cropping systems as well as the dietary food habits of the people of the region (Kumar et al., 2008). The semi perishability and bulkiness are the innate characteristic of potato that causes problems in its marketing. Marketing of potato in North eastern states of India is further constrained by hilly topography that comprises about 70 per cent of the total area (Sah et al., 2011), limits its movement which ultimately affects the resource 
poor farmers of the region. Marketing and storage were also identified as important weaknesses of potato production in India. Saikia (2001) highlighted that the facilities of storage, processing and marketing are deficient for perishable commodities as technological constraint for agricultural development in north eastern region of India. Owing to the highlighted weaknesses, the rural marketing in the region is confined primarily to unorganized sector with domination of private traders.

Though potato is one of major commercial crops of North-eastern India, farmers are facing problems in utilizing various sources of information for all round development. Considering these issues, a research study entitled "Information sources utilization among potato farmers in North East India" was undertaken with an objective to examine the various sources of information sources and level of use among the potato farmers.

\section{METHODOLOGY}

Four highest potato growing states of North-East region namely Assam, Meghalaya, Nagaland and Tripura were selected for the present study. From each of the selected states one highest potato producing district and from each selected districts one highest potato producing block was selected purposively. Further a list of potato growing villages was prepared under each of the selected blocks and four villages were selected randomly from each of the selected blocks. Thus a total sample of 480 farmers was selected by simple random technique including 30 potato farmers having at least three years of farming experience. Face-to-face personal interview was conducted for collection of data using pre tested interview schedule. Data analysis was done using SPAR 2.0 software.

\section{RESULTS AND DISCUSSION}

Table 1 depicts the sources of information utilization by the potato farmers of Assam. It was found that among the different sources of information, informal sources of information ranked first, followed by massmedia and formal sources of information. In case of using informal information sources only 25.00 per cent of the respondents made contact with progressive farmers most often followed by most $(53.33 \%)$ of the farmers who had active contact with neighbours and 86.67 per cent of farmers never contacted their relatives for using informal sources of information. In case of using the different mass media sources, majority $(73.33 \%)$ of the potato farmers of Assam used mobile phones most often as mass media information sources. Further, majority (59.17\%) of them used television sometimes, while 100.00 per cent of them never used radio and videoconferencing. In case of formal information sources, majority $(64.17 \%)$ of the respondents made contact with VEW most often. Further, 51.67 per cent of them contacted Agriculture Officers sometimes while 100.00 per cent of them had never contact with NGOs. This finding was in line with the findings of Singh et al. (2004). Overall analysis revealed that mean score of using informal sources of information was the highest (0.56) among all other sources of information utilized by the farmers.

From Table 2, it was found that among the use of different sources of information, informal information sources ranked first followed by formal sources of information and mass-media. In case of using informal information sources only 26.67 per cent of the potato farmers made contact with progressive farmers most often, followed by most $(65.00 \%)$ of the farmers who contacted neighbours and 49.17 per cent of them never contacted their relatives under informal sources of information. In case of using formal information sources majority (30.83\%) of the respondents made contact with VEW most often. Further, 90.83 per cent of them contacted Agriculture Officers sometimes while 100.00 per cent of them had never contact with NGOs. In case of using the different mass media sources, majority (76.67\%) of the potato farmers of Meghalaya used mobile phones most often as mass media information source. Further, majority (50.83\%) of them used television sometimes, while 100.00 per cent of them never used radio and videoconferencing. These findings were similar to the findings of Singh et al. (2004). Overall analysis revealed that mean score of using informal information sources was the highest $(0.804)$ among the other sources of information utilized by the farmers.

Table 3 indicates the sources of information utilization by the potato farmers of Nagaland. It was found that among the different sources of information utilization, informal sources of information ranked first followed by formal sources of information and massmedia information sources. In case of using informal information sources only 11.67 and 47.50 per cent of the potato growers made contact with friends most often 
Table 1. Distribution of potato farmers based on their utilization of information sources in Assam (N=120)

\begin{tabular}{|c|c|c|c|c|c|c|c|c|}
\hline \multirow{2}{*}{ Information sources } & \multicolumn{2}{|c|}{ Most often } & \multicolumn{2}{|c|}{ Sometimes } & \multicolumn{2}{|c|}{ Never } & \multirow{2}{*}{ MS } & \multirow{2}{*}{ Rank } \\
\hline & No. & $\%$ & No. & $\%$ & No. & $\%$ & & \\
\hline Radio & 0 & $(0.00)$ & 0 & $(0.00)$ & 120 & $(100.00)$ & 0.479 & II \\
\hline Television & 45 & $(37.50)$ & 71 & $(59.17)$ & 4 & (3.33) & & \\
\hline Exhibition & 0 & $(0.00)$ & 22 & $(18.33)$ & 98 & $(81.67)$ & & \\
\hline Printed media (Poster, Folder, etc) & 0 & $(0.00)$ & 21 & $(17.50)$ & 99 & $(82.50)$ & & \\
\hline Newspaper & 11 & $(9.17)$ & 68 & $(56.67)$ & 41 & $(34.17)$ & & \\
\hline Internet & 1 & $(0.83)$ & 6 & $(5.00)$ & 113 & (94.17) & & \\
\hline Mobile & 88 & (73.33) & 25 & (20.83) & 7 & $(5.83)$ & & \\
\hline Smartphone, SMS based services & 0 & $(0.00)$ & 15 & $(12.50)$ & 105 & $(87.50)$ & & \\
\hline Videoconferencing & 0 & $(0.00)$ & 0 & $(0.00)$ & 120 & $(100.00)$ & & \\
\hline VLW/VEW & 77 & $(64.17)$ & 35 & $(29.17)$ & 8 & $(6.66)$ & 0.408 & III \\
\hline Agriculture Officer & 16 & (13.33) & 62 & $(51.67)$ & 42 & $(35.00)$ & & \\
\hline SDAO & 0 & $(0.00)$ & 28 & $(23.33)$ & 92 & $(76.67)$ & & \\
\hline $\mathrm{HO}$ & 0 & $(0.00)$ & 7 & $(5.83)$ & 103 & $(85.83)$ & & \\
\hline KVK & 20 & $(16.67)$ & 25 & (20.83) & 75 & $(62.50)$ & & \\
\hline ATMA & 2 & $(1.67)$ & 19 & (15.83) & 99 & $(82.50)$ & & \\
\hline NGOs & 0 & $(0.00)$ & 0 & $(0.00)$ & 120 & $(100)$ & & \\
\hline ICAR & 6 & $(5.00)$ & 23 & (19.17) & 91 & $(75.83)$ & & \\
\hline Friends & 7 & $(5.83)$ & 47 & (39.17) & 66 & $(55.00)$ & 0.560 & $\mathrm{I}$ \\
\hline Relatives & 0 & $(0.00)$ & 16 & (13.33) & 104 & $(86.67)$ & & \\
\hline Neighbours & 7 & $(5.83)$ & 64 & (53.33) & 49 & (40.83) & & \\
\hline Progressive farmers & 30 & $(25.00)$ & 54 & $(45.00)$ & 36 & $(30.00)$ & & \\
\hline
\end{tabular}

Table 2. Distribution of potato farmers based on their utilization of information sources in Meghalaya (N=120)

\begin{tabular}{|c|c|c|c|c|c|c|c|c|}
\hline \multirow{2}{*}{ Information sources } & \multicolumn{2}{|c|}{ Most often } & \multicolumn{2}{|c|}{ Sometimes } & \multicolumn{2}{|c|}{ Never } & \multirow{2}{*}{ MS } & \multirow{2}{*}{ Rank } \\
\hline & No. & $\%$ & No. & $\%$ & No. & $\%$ & & \\
\hline Radio & 0 & $(0.00)$ & 0 & $(0.00)$ & 120 & $(100.00)$ & 0.510 & III \\
\hline Television & 37 & $(30.83)$ & 61 & $(50.83)$ & 22 & (18.33) & & \\
\hline Exhibition & 0 & $(0.00)$ & 17 & $(14.17)$ & 103 & $(85.83)$ & & \\
\hline Printed media (Poster, Folder, etc) & 0 & $(0.00)$ & 14 & $(11.67)$ & 106 & $(88.33)$ & & \\
\hline Newspaper & 17 & (14.17) & 51 & $(42.50)$ & 52 & (43.33) & & \\
\hline Internet & 19 & $(15.83)$ & 41 & $(34.17)$ & 60 & $(50.00)$ & & \\
\hline Mobile & 92 & (76.67) & 20 & $(16.67)$ & 8 & $(6.67)$ & & \\
\hline Smartphone, SMS based services & 0 & $(0.00)$ & 17 & (14.17) & 103 & $(85.83)$ & & \\
\hline Videoconferencing & 0 & $(0.00)$ & 0 & $(0.00)$ & 120 & $(100.00)$ & & \\
\hline VLW/VEW & 32 & $(26.66)$ & 44 & $(36.67)$ & 44 & $(36.67)$ & 0.554 & II \\
\hline Agriculture Officer & 9 & $(7.50)$ & 109 & $(90.83)$ & 2 & $(1.67)$ & & \\
\hline SDAO & 0 & $(0.00)$ & 25 & $(20.83)$ & 95 & (79.17) & & \\
\hline $\mathrm{HO}$ & 33 & $(27.50)$ & 30 & $(25.00)$ & 57 & $(47.50)$ & & \\
\hline $\mathrm{KVK}$ & 12 & $(10.00)$ & 62 & $(51.67)$ & 46 & (38.33) & & \\
\hline ATMA & 1 & $(0.83)$ & 32 & $(26.67)$ & 87 & $(72.50)$ & & \\
\hline NGOs & 0 & $(0.00)$ & 0 & $(0.00)$ & 120 & $(100.00)$ & & \\
\hline ICAR & 37 & (30.83) & 48 & $(40.00)$ & 35 & (29.17) & & \\
\hline Friends & 22 & (18.33) & 65 & $(54.17)$ & 33 & $(27.50)$ & 0.804 & I \\
\hline Relatives & 18 & $(15.00)$ & 43 & $(35.83)$ & 59 & (49.17) & & \\
\hline Neighbours & 1 & $(0.83)$ & 78 & $(65.00)$ & 41 & (34.17) & & \\
\hline Progressive farmers & 32 & $(26.67)$ & 54 & $(45.00)$ & 34 & (28.33) & & \\
\hline
\end{tabular}


and sometimes and 65.00 per cent farmers never contacted progressive farmers using informal sources of information needs. In case of using formal information sources, majority (24.17\%) of the potato farmers made contact with VEW most often. Further, 71.67 per cent of them contacted Agriculture Officers sometimes, while 100.00 per cent of them had never contact with NGOs. In case of using the different mass media sources, majority 39.17 per cent and 44.17 per cent of the potato farmers of Nagaland used mobile phones most often and sometimes as their media information sources, while 100.00 per cent of them never used radio and videoconferencing. These findings were similar to the findings of Singh et al. (2004). Overall analysis revealed that mean score of using informal information sources was the highest $(0.525)$ among other sources.

From Table 4, it was evident that among the different sources of information utilization, informal sources of information ranked first followed by mass-media and formal sources of information respectively. In case of using informal information sources only 20.83 per cent of the respondents made contact with progressive farmers most often followed by most (59.17\%) of the farmers contacted their neighbours and 86.67 per cent of the potato growers never contacted their relatives for their informal sources of information needs. In case of using the different mass media sources, majority $(73.33 \%)$ of the potato farmers of Tripura used mobile phones most often as mass media information source. Further, majority $(59.17 \%)$ of them used television sometimes, while 100.00 per cent of them never used radio and videoconferencing. In case of using formal information sources majority $(50.83 \%)$ of the respondents made contact with VEW most often. Further, 61.67 per cent of them contacted Agriculture Officers sometimes while 100.00 per cent of them had never contact with NGOs. This finding was in similar to the findings of Singh et al. (2004). Further, Overall analysis revealed that mean score of using informal information sources was the highest (0.562) among the other sources of information utilized by the farmers.

Table 5 revealed that 71.68 per cent of the potato growers of Assam had medium level of information sources utilization; followed by 14.16 per cent of them had low as well as high level of information sources utilization respectively. In case of potato farmers of Meghalaya, 68.33 per cent of them had medium level of information sources utilization, followed by 19.17 per cent and 12.50 per cent of them having low and high level of information sources utilization. In case of potato growers of Nagaland, majority $(70.00 \%)$ of them had medium level of information sources utilization, followed by 17.50 per cent and 12.50 per cent of them having high and low level of information sources utilization respectively. Jha \& Thorie (2012) in their study found that only 15.18 per cent of the potato growers had high exposure to mass media sources of information. In case of potato growers of Tripura, majority $(52.50 \%)$ of the respondents had medium level of information sources utilization while 32.50 per cent of them had low and 15.00 per cent of them had high information sources utilization. In case of overall potato growers of Northeast, 72.29 per cent of them had medium level of information sources utilization, while 14.38 per cent of them had low and 13.33 per cent of them had high level of information sources utilization. These findings were in accordance with the findings of Suresh (2004), Nagesh (2006) and Shree et al. (2020).

Table 6 indicates the significant difference in information sources utilization pattern among the potato growers of selected NE states with respect to sustainable potato cultivation. It was observed that there exists a significant difference in information sources utilization pattern between the potato growers of Assam and Meghalaya, Meghalaya and Nagaland as well as Tripura and Meghalaya at $1 \%$ level of probability, whereas there was no significant difference in information sources utilization pattern between the potato growers of Nagaland and Tripura as well as Tripura and Assam.

\section{CONCLUSION}

Majority of the potato farmers of NE states comprising Assam, Meghalaya, Nagaland and Tripura used mobile as their most preferred mass media information source for obtaining pertinent information related to sustainable potato cultivation. In case of formal information sources, potato farmers of Assam, Nagaland and Tripura used VEW as their primary information source but potato farmers of Meghalaya obtained required information from ICAR research institute. In case of informal information sources, potato farmers of Nagaland obtained relevant information from friends as primary information source, whereas potato farmers from Assam, Meghalaya and Tripura preferred 
Table 3. Distribution of potato farmers based on their utilization of information sources in Nagaland (N=120)

\begin{tabular}{|c|c|c|c|c|c|c|c|c|}
\hline \multirow[t]{2}{*}{ Information sources } & \multicolumn{2}{|c|}{ Most often } & \multicolumn{2}{|c|}{ Sometimes } & \multicolumn{2}{|c|}{ Never } & \multirow[t]{2}{*}{ MS } & \multirow[t]{2}{*}{ Rank } \\
\hline & No. & $\%$ & No. & $\%$ & No. & $\%$ & & \\
\hline Radio & 0 & $(0.00)$ & 0 & $(0.00)$ & 120 & $(100)$ & 0.455 & III \\
\hline Television & 26 & $(21.67)$ & 46 & (38.33) & 48 & $(40.00)$ & & \\
\hline Exhibition & 0 & $(0.00)$ & 20 & $(16.67)$ & 100 & $(100)$ & & \\
\hline Printed media (Poster, Folder, etc) & 0 & $(0.00)$ & 31 & $(25.83)$ & 89 & $(74.17)$ & & \\
\hline Newspaper & 17 & (14.17) & 51 & $(42.50)$ & 52 & $(43.33)$ & & \\
\hline Internet & 19 & $(15.83)$ & 41 & (34.17) & 60 & $(50.00)$ & & \\
\hline Mobile & 47 & (39.17) & 53 & $(44.17)$ & 20 & $(16.67)$ & & \\
\hline Smartphone, SMS based services & 0 & $(0.00)$ & 31 & $(25.83)$ & 89 & $(74.17)$ & & \\
\hline Videoconferencing & 0 & $(0.00)$ & 0 & $(0.00)$ & 120 & $(100)$ & & \\
\hline VLW/VEW & 29 & $(24.17)$ & 37 & $(30.83)$ & 54 & $(45.00)$ & 0.466 & II \\
\hline Agriculture Officer & 4 & $(3.33)$ & 86 & (71.67) & 30 & $(25.00)$ & & \\
\hline SDAO & 0 & $(0.00)$ & 25 & $(20.83)$ & 95 & (79.17) & & \\
\hline $\mathrm{HO}$ & 25 & $(20.83)$ & 36 & $(30.00)$ & 59 & $(49.17)$ & & \\
\hline $\mathrm{KVK}$ & 12 & $(10.00)$ & 62 & $(51.67)$ & 46 & (38.33) & & \\
\hline ATMA & 8 & $(6.67)$ & 46 & $(38.33)$ & 66 & $(55.00)$ & & \\
\hline NGOs & 0 & $(0.00)$ & 0 & $(0.00)$ & 120 & $(100)$ & & \\
\hline ICAR & 2 & $(1.67)$ & 41 & (34.17) & 67 & $(55.83)$ & & \\
\hline Friends & 14 & (11.67) & 57 & $(47.50)$ & 49 & (40.83) & 0.525 & I \\
\hline Relatives & 11 & $(9.17)$ & 41 & $(34.17)$ & 68 & $(56.66)$ & & \\
\hline Neighbours & 1 & $(0.83)$ & 52 & (43.33) & 67 & $(55.83)$ & & \\
\hline Progressive farmers & 8 & $(6.67)$ & 34 & $(28.33)$ & 78 & $(65.00)$ & & \\
\hline
\end{tabular}

Table 4. Distribution of potato farmers based on their utilization of information sources in Tripura (N=120)

\begin{tabular}{|c|c|c|c|c|c|c|c|c|}
\hline \multirow[t]{2}{*}{ Information sources } & \multicolumn{2}{|c|}{ Most often } & \multicolumn{2}{|c|}{ Sometimes } & \multicolumn{2}{|c|}{ Never } & \multirow[t]{2}{*}{ MS } & \multirow[t]{2}{*}{ Rank } \\
\hline & No. & $\%$ & No. & $\%$ & No. & $\%$ & & \\
\hline Radio & 0 & $(0.00)$ & 0 & $(0.00)$ & 120 & $(100)$ & 0.485 & II \\
\hline Television & 45 & $(37.50)$ & 71 & $(59.17)$ & 4 & $(3.33)$ & & \\
\hline Exhibition & 0 & $(0.00)$ & 22 & $(18.33)$ & 98 & (81.67) & & \\
\hline Printed media (Poster, Folder, etc) & 0 & $(0.00)$ & 21 & $(17.50)$ & 99 & $(82.50)$ & & \\
\hline Newspaper & 13 & $(10.83)$ & 70 & $(58.33)$ & 37 & $(30.83)$ & & \\
\hline Internet & 1 & $(0.83)$ & 6 & $(5.00)$ & 113 & (94.17) & & \\
\hline Mobile & 88 & $(73.33)$ & 25 & $(20.83)$ & 7 & $(5.83)$ & & \\
\hline Smartphone, SMS based services & 0 & $(0.00)$ & 15 & $(12.50)$ & 105 & $(87.50)$ & & \\
\hline Videoconferencing & 0 & $(0.00)$ & 0 & $(0.00)$ & 120 & $(100)$ & & \\
\hline VLW/VEW & 61 & $(50.83)$ & 28 & $(23.33)$ & 31 & $(25.83)$ & 0.420 & III \\
\hline Agriculture Officer & 11 & $(9.17)$ & 74 & $(61.67)$ & 35 & (29.17) & & \\
\hline SDAO & 0 & $(0.00)$ & 28 & $(23.33)$ & 92 & (76.67) & & \\
\hline $\mathrm{HO}$ & 0 & $(0.00)$ & 7 & $(5.83)$ & 113 & (94.17) & & \\
\hline $\mathrm{KVK}$ & 11 & $(9.17)$ & 32 & $(26.67)$ & 77 & (64.17) & & \\
\hline ATMA & 17 & (14.17) & 14 & (11.67) & 89 & (74.17) & & \\
\hline NGOs & 0 & $(0.00)$ & 0 & $(0.00)$ & 120 & $(100)$ & & \\
\hline ICAR & 20 & (16.67) & 31 & $(25.83)$ & 69 & $(57.50)$ & & \\
\hline Friends & 15 & $(12.50)$ & 55 & $(45.83)$ & 50 & (41.67) & 0.562 & I \\
\hline Relatives & 0 & $(0.00)$ & 16 & (13.33) & 104 & (86.67) & & \\
\hline Neighbours & 1 & $(0.83)$ & 71 & $(59.17)$ & 48 & $(40.00)$ & & \\
\hline Progressive farmers & 25 & $(20.83)$ & 46 & $(38.33)$ & 49 & $(40.83)$ & & \\
\hline
\end{tabular}


Table 5. Level of information sources utilized by the potato farmers $(\mathrm{N}=\mathbf{4 8 0})$

\begin{tabular}{llllll}
\hline NE states & Level & No. & $\%$ & MS & SD \\
\hline Assam & Low $(<7.20)$ & 17 & 14.16 & 10.23 & 3.07 \\
& Medium $(7.20-13.30)$ & 86 & 71.68 & & \\
& High $(>13.30)$ & 17 & 14.16 & & \\
Meghalaya & Low $(<9.50)$ & 23 & 19.17 & 12.79 & 3.34 \\
& Medium $(9.50-16.10)$ & 82 & 68.33 & & \\
& High $(>16.10)$ & 15 & 12.50 & & \\
Nagaland & Low $(<7.30)$ & 15 & 12.50 & 10.38 & 3.04 \\
& Medium $(7.30-13.30)$ & 84 & 70.00 & & \\
Tripura & High $(>13.30)$ & 21 & 17.50 & & \\
& Low $(<10)$ & 39 & 32.50 & 10.40 & 3.31 \\
& Medium $(10-13.70)$ & 63 & 52.50 & & \\
Overall & High $(>13.70)$ & 18 & 15.00 & & \\
farmers & Low $(<7.50)$ & 69 & 14.38 & 10.95 & 3.37 \\
& Medium $(7.50-14.30)$ & 347 & 72.29 & & \\
& High $>14.30)$ & 64 & 13.33 & & \\
\hline
\end{tabular}

to obtain required information from progressive farmers. Analysis also revealed that potato farmers preferred to utilize informal information sources more than formal as well as the mass media sources. It is therefore recommended to popularize the strategic use of mass media including user friendly ICT tools for better and faster outreach to the target farmers. This will be helpful
Table 6. Comparative account of information sources utilized for sustainable potato cultivation

\begin{tabular}{llll}
\hline Name of the state & $(\mu)$ & Z value & Probability \\
\hline Assam & 10.23 & $-6.015^{* *}$ & $<0.01$ \\
Meghalaya & 12.79 & & \\
Meghalaya & 12.79 & $5.757^{* *}$ & $<0.01$ \\
Nagaland & 10.38 & & \\
Nagaland & 10.38 & 0.090 & $>0.05$ \\
Tripura & 10.40 & & \\
Tripura & 10.40 & -0.338 & $>0.05$ \\
Assam & 10.23 & & \\
Tripura & 10.40 & $5.488^{* *}$ & $<0.01$ \\
Meghalaya & 12.79 & & \\
Assam & 10.23 & -0.453 & $>0.05$ \\
Nagaland & 10.38 & & \\
\hline
\end{tabular}

** Significant at $1 \%$ level of probability

in providing the updated information to the farmers with accuracy, authenticity as well as at the right time of their need.

\section{CONFLICTS OF INTEREST}

The authors declare that they have no conflicts of interest.

\section{REFERENCES}

Jha, K.K. and Thorie, V. (2012). Entrepreneurial characteristics of potato growers in Kohima, Nagaland. Nagaland University Research Communication. Pp. 77-83.

Kumar, S.; Singh, D.; Singh, D. K.; Yadav, R. N.; Sharma, V. K. and Ali, N. (2008). Study the relationship of independent variables with technological gap of potato growers. Progressive Research. 3 (1) : 67-69.

Nagesh, P. (2006). Study on entrepreneurial behaviour of pomegranate growers in Bagalkot district of Karnataka. M.Sc. (Agri. Thesis, University of Agricultural Sciences, Dharwad.

NHB (2018). Horticultural Statistics at a glance 2018. Horticulture Statistics Division, Department of Agriculture, Cooperation \& Farmers'Welfare, Ministry of Agriculture \& Farmers' Welfare Government of India

Sah, U.; Dubey, S. K. and Sharma, J.P. (2011). Potato marketing in north east region of India: A diagnostic study. J. of Comm. Mobil. and Sust. Deve., 6 (2):194-201.

Saikia, A. (2001). Performance of agricultural economy of the North Eastern India: Constraints and priorities. presented in workshop "Prioritization of Strategies for Agricultural Development in Northeastern India" organized by National Centre for Agricultural Economics and Policy Research (NCAP).

Singh, M.; Sharma, S.K. and Kakran, M.S. (2004). Effectiveness of different communication channels on mustard growers. Indian Res.J.Ext. Edu., 4 (7) : 50-54.

Suresh, S. (2004). Entrepreneurial behaviour of milk producers in Chittoor district of Andra Pradesh - A critical study. M.V.Sc Thesis, Achrya N G Ranga Agricultural University. Hyderabad.

Shree, D.A.; Nithya; Rekha, R. and Roopa, N. (2020). Socio-economic assessment of farm women in rice cultivation. Indian Res.J.Ext. Edu., 55(4) : 56-60. 